TI 2017-053/VII

Tinbergen Institute Discussion Paper
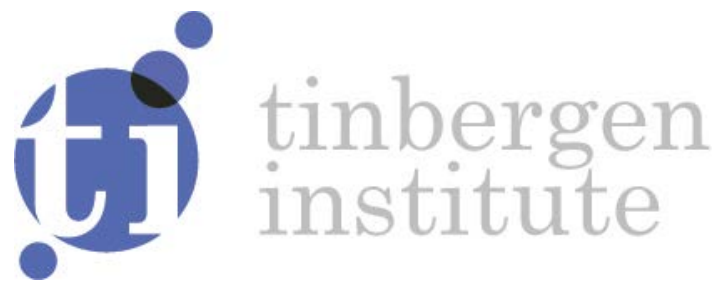

\title{
Signaling in Auctions: Experimental Evidence
}

\section{Revised: 7-7-2017}

Olivier Bos ${ }^{1}$

Francisco Gomez-Martinez ${ }^{2}$

Sander Onderstal ${ }^{3}$

Tom Truyts ${ }^{4}$

\footnotetext{
${ }^{1}$ Panthéon-Assas University, France

${ }^{2}$ Universidad Carlos III de Madrid, Spain

${ }^{3}$ University of Amsterdam and Tinbergen Institute, The Netherlands

${ }^{4}$ Saint-Louis University and University of Leuven, Belgium
} 
Tinbergen Institute is the graduate school and research institute in economics of Erasmus University Rotterdam, the University of Amsterdam and VU University Amsterdam.

Contact: discussionpapers@tinbergen.nl

More TI discussion papers can be downloaded at http://www.tinbergen.nl

Tinbergen Institute has two locations:

Tinbergen Institute Amsterdam

Gustav Mahlerplein 117

1082 MS Amsterdam

The Netherlands

Tel.: $+31(0) 205984580$

Tinbergen Institute Rotterdam

Burg. Oudlaan 50

3062 PA Rotterdam

The Netherlands

Tel.: +31(0)104088900 


\title{
Signalling in Auctions: Experimental Evidence
}

\author{
Olivier Bos*, Francisco Gomez-Martinez**, Sander Onderstal***, Tom Truyts****
}

June 28, 2017

\begin{abstract}
:
We study the relative performance of the first-price sealed-bid auction and the secondprice sealed-bid auction in a laboratory experiment where bidders can signal information through their bidding behaviour to an outside observer. We consider two different information settings: the auctioneer reveals either the identity of the winning bidder only, or she also reveals the winner's payment to an outside observer. We find that the first-price sealed-bid auction in which the winner's payment is revealed outperforms the other mechanisms in terms of revenue and efficiency. Our findings may have implications for the design of charity auctions, art auctions, and spectrum auctions.
\end{abstract}

Keywords: Auctions; Signalling; Experiments

JEL classification: C92; D44; D82

Acknowledgments: We are grateful to Francis Bloch, David Ettinger and Jean-Marc Tallon, and participants at the CREED seminar in Amsterdam for their helpful comments. This research has been conducted as part of the project Labex MME-DII (ANR11-LBX-0023-01). We also thank the ANR DCPG and the University of Amsterdam Research Priority Area in Behavioral Economics for their financial support. Tom Truyts gratefully acknowledges financial support from the French-speaking Belgian community ARC project n¹5/20-072, "Social and Economic Network Formation under Limited Farsightedness: Theory and Applications", Université Saint-Louis - Bruxelles, October 2015 - September 2020.

\footnotetext{
*LEMMA- Department of Economics, Panthéon-Assas University, olivier.bos@u-paris2.fr.

** Department of Economics, Universidad Carlos III de Madrid, fragomez@eco.uc3m.es.

*** University of Amsterdam and Tinbergen Institute, onderstal@uva.nl.

**** CEREC, Saint-Louis University - Brussels and Center for Economic Studies, University of Leuven, tom.truyts@usaintlouis.be.
} 


\section{Introduction}

In many auction settings, bidders care about how their behaviour in the auction is interpreted by others. Market analysts can consider the performance of a firm in an auction, winning or losing, as a signal of the firm's management quality, financial position, or confidence in its technological edge on the competition. ${ }^{1}$ Signalling has also been shown to be an important motivator for bidders in charity and art auctions: winning a Van Gogh painting comes with a great deal of prestige, whereas failing to win a charity auction may leave some wondering about the losing bidder's true financial position or magnanimity. ${ }^{2}$ In such settings, signalling concerns constitute an additional component in a bidder's bidding strategy. In the past two decades, the theoretical literature has devoted ample attention to signalling in auctions. ${ }^{3}$

A key finding from this literature is that an auction's equilibrium revenue depends on both the auction format used and the kind of information that the auctioneer reveals about the outcome of the auction. In settings where bidders have an incentive to overstate their private information, the first-price (FP) sealed-bid auction and secondprice (SP) sealed-bid auction yield the same expected revenue in a separating equilibrium if the auctioneer reveals only the winner's identity (Giovannoni and Makris, 2014) or the winner's identity and bid (Goeree, 2003; Haile, 2003; Katzman and RhodesKropf, 2008; Giovannoni and Makris, 2014). ${ }^{4}$ Giovannoni and Makris (2014) tie these revenue-equivalence results together by eliciting conditions which guarantee that an auction's expected revenue only depends on the information revealed, independently of the auction format used. In contrast, if the winner's payment is revealed (rather than her bid), revenue equivalence breaks down. In that case, the SP auction dominates the FP auction in terms of expected revenue (Giovannoni and Makris, 2014; Bos and Truyts, 2017). Finally, revealing either the winner's bid or the winner's payment increases revenue in both the first-price and the second-price sealed-bid auction compared to the case where only the winner's identity is revealed (Giovannoni and Makris, 2014; Bos and Truyts, 2017).

In this paper, we experimentally test these results using Bos and Truyts' (2017) framework We consider a symmetric independent private values setting in which an

\footnotetext{
${ }^{1}$ Liu (2012) argues that signalling incentives could arise in bidding contests where the winning bidder issues equity or debt for financing her payment.

2 Mandel (2009) distinguishes three main motives for buying art: investment, direct consumption, and signalling, and suggests that the latter two explain the old puzzle as to why art systematically underperforms as an investment compared to bonds and equity. Charities often raise funds by auctioning objects provided to them by celebrities (Schram and Onderstal, 2009). A broad theoretical and empirical literature suggests that signalling and status are important motives for contributions to charities. Glazer and Konrad (1996) and Harbaugh (1998a,b) show that signalling is an important factor to explain patterns in donations to universities.

3 See Goeree (2003); Das Varma (2003); Haile (2003); Katzman and Rhodes-Kropf (2008); Monar and Virag (2008); Liu (2012); Marinovic (2014); Giovannoni and Makris (2014); and Bos and Truyts (2017). ${ }^{4}$ Goeree (2003) and Das Varma (2003) show that in settings where bidders want to understate their private information, separating equilibria may fail to exist.
} 
outside observer is partly informed about the auction outcome and uses this information to update her beliefs about the bidders' values. We consider two different information settings: the auctioneer reveals either the identity of the winning bidder to the outside observer only, or she also reveals the winner's payment.

As Turocy (2009) notes, signalling games are hard for humans to play. This may explain why there are only a small number of experiments regarding signalling games. Moreover, most of these experiments focus on equilibrium selection, given the usual equilibrium multiplicity in signalling games. ${ }^{5}$ Auctions with signalling have hardly been analysed in the lab. ${ }^{6}$ To the best of our knowledge, the only other experimental paper on signalling in auctions so far is by Fonseca et al. (2016). They consider a setting where bidders can signal their productivity to firms that are hiring on a labour market. Fonseca et al. focus on several information disclosure policies within the same auction format: the first-price sealed-bid auction. While they find that signalling opportunities lead to more aggressive bids, they observe consistent underbidding compared to equilibrium. Our experimental results complement theirs in that our design facilitates betweenauction comparisons.

Our main result is that the first-price sealed-bid auction in which the winner's payment is revealed outperforms the other mechanisms in terms of revenue and efficiency. In both auctions, we observe more aggressive bidding compared to control treatments in which the outside observer's estimates do not affect the bidders' payoffs. This underlines the importance of revealing information to outsiders when bidders care about how their behaviour is interpreted by others. However, like Fonseca et al. (2016), we find underbidding relative to the equilibrium prediction. Underbidding is particularly striking for the second-price sealed-bid auction where the winner's payment is revealed to the outside observer. As a result, we do not find support for the theoretical prediction that the second-price auction yields more revenue than the firstprice sealed-bid auction in this information regime. Moreover, revealing the winner's payment only boosts revenue in the first-price sealed-bid auction, not in the secondprice sealed-bid auction. The latter finding is also inconsistent with the theory.

The remainder of this paper is structured as follows. In Section 2, we describe our experimental design and protocol. Section 3 includes the theoretical results and the hypotheses tested. Section 4 contains our experimental findings. Section 5 concludes.

\footnotetext{
5 Brandts and Holt (1993), de Haan et al. (2011), Drouvelis et al. (2012), and Jeitschko and Normann (2012).

${ }^{6}$ Previous experimental works on auctions focused on the importance of disclosure policies. Either bids are revealed to bidders (see, e.g., Cason et al., 2011; Dufwenberg and Gneezy, 2002; and Neugebauer and Selten, 2006), bidders' types are revealed to bidders (see, e.g., Andreoni et al., 2007), or the auctioneer releases some public information (see, e.g., Goeree and Offerman, 2002). However, none of these investigate signalling concerns, or how revealing information to an outside observer affects bidding strategies, efficiency and expected revenues.
} 


\section{Experimental design and protocol}

The experiment was computerized ${ }^{7}$ and run at the CREED laboratory of the University of Amsterdam. We employed a full $2 \times 2 \times 2$ factorial design varying (between subjects) the auction type (FP and SP), the information about the auction outcome that is communicated to the outside observer (with or without information about the winner's payment), and whether the bidders' payoffs depend on the outside observer's estimate (in the main treatments, it did, in the control treatments, it did not). Table 1 summarizes the resulting eight treatments of the experiment. The control treatments serve as a benchmark when comparing results between auction types.

Each treatment was comprised of seven groups of four participants. All 224 participants took part in only one session each. At the start of each session, we randomly allocated participants over the computers so they could not infer which other participants were in the same group. We provided computerized instructions to the participants. The instructions for treatment FPWP can be found in Online Appendix A. ${ }^{8}$ Before the experiment started, participants answered test questions to make sure that they understood the experimental protocol. ${ }^{9}$ Sessions lasted between 45 and 75 minutes. Payment consisted of a show-up fee of 7 euros, plus a payoff related to the total profits earned in the 30 rounds. The exchange rate was 1 euro for 50 experimental points. On average, participants earned 16.70 euros (including the show-up fee).

Table 1: Experimental design

\begin{tabular}{lccc}
\hline Treatment & Auction & $\begin{array}{c}\text { Information to the outside } \\
\text { observer }\end{array}$ & $\begin{array}{c}\text { Do bidders' payoffs depend } \\
\text { on outside observer's } \\
\text { estimate? }\end{array}$ \\
\hline FPW & FP & The winner & Yes \\
FPWP & FP & The winner and her payment & Yes \\
SPW & SP & The winner & Yes \\
SPWP & SP & The winner and her payment & Yes \\
FPW control & FP & The winner & No \\
FPWP control & FP & The winner and her payment & No \\
SPW control & SP & The winner & No \\
SPWP control & SP & The winner and her payment & No \\
\hline
\end{tabular}

\footnotetext{
7 The program was written using PHP and mySQL.

${ }^{8}$ The instructions of the other treatments are available from the authors upon request.

${ }^{9}$ These questions are available from the authors upon request.
} 
In all sessions, participants interacted in fixed groups of four (no rematching). In each of the 30 rounds of a session, a fictitious good was auctioned. In each round, one group member was randomly chosen by the computer to play the role of the outside observer. The remaining three group members were bidders in an auction. We chose to let subjects interact in fixed groups, and have them take turns playing the role of the outside observer in their group. This was done to foster the learning needed to reach a perfect Bayesian equilibrium, which crucially requires a coordination between the bidders' strategies and the outside observer's beliefs. Role switching also renders bidder collusion more difficult.

At the start of each round, all bidders were privately informed about their value for the good. Both the bidders and the outside observer were informed that all values were independently drawn according to a uniform distribution on the set $\{1,2,3, \ldots, 100\}$. For the sake of comparability between treatments, we kept the value draws constant across treatments. In the auction, each of the three bidders independently submitted a bid for the fictitious good from the set $\{0,1,2, \ldots, 200\}$. The bidder with the highest bid won the good. In the FP auction, the winner paid his own bid, while in the SP auction, the winner paid the second highest bid. Ties were resolved randomly. In the main treatments, the bidder payoffs depended on both the outcome of the auction, and the estimate of the outside observer. The winning bidder obtained the difference between his value and payment. In addition, each bidder, win or lose, received half of the outside observer's estimate of his value.

After the auction, the outside observer was asked to guess the values of each of the three bidders after obtaining information about the outcome of the auction. In all treatments, she was informed about which bidder won the auction. In some treatments, she also obtained information regarding how much the winner paid. The payoffs of the outside observer depended on the accuracy of her estimates. Once she had entered value estimates for all bidders, the computer drew one of the three bidders' estimates at random. When the outside observer's estimate for this bidder deviated $x$ points from the actual value, her payoff was equal to $40-x$.

\section{Theoretical predictions}

In this section, we describe the theoretical predictions. The analysis follows straightforwardly from Bos and Truyts (2017). Like them, we restrict our attention to risk-neutral bidders and perfect Bayesian Nash equilibria that survive Banks and Sobel's (1987) D1 criterion (referred to as "equilibrium" in the remainder of this paper). Table 2 contains equilibrium predictions for all treatments. The formal derivations are in Online Appendix B.

In all treatments, a unique strictly increasing and symmetric equilibrium bidding curve exists. For the control treatments, the existence of an outside observer has no effect on 
the bidders' payoffs. Therefore, the predictions are standard, and imply revenue equivalence across treatments (see, e.g., Vickrey, 1961). If only the identity of the winner is revealed to the outside observer, bidders' payoffs when winning are increased by half the difference between the outside observer's value estimates for winners and losers. Equilibrium bids are inflated by this number compared to the control treatments. In Online Appendix B, we show that a bidder's payoff from winning the auction (and hence his equilibrium bid) is increased by about 22 .

If the winner's payment is also revealed, then the bidders will also take into account how the outside observer updates her beliefs about the bidders' values in function of the observed payment. In equilibrium, the winner's value is exactly revealed to the outside observer in the FP auction, since the equilibrium bidding curve is strictly increasing. Therefore, the outside observer will perfectly predict the winner's value. Moreover, bidders will take into account that when losing, the outside observer estimates their value to be equal to half the winner's value. A low-value bidder is better off, in terms of the outside observer's equilibrium estimate, by losing against a sufficiently high-value bidder, rather than by winning the auction. In the opposite case, the difference between winning and losing is large when viewed in terms of the outside observer's equilibrium estimate for high-value bidders. As a result, the equilibrium bids of low [high] value bidders are lower [higher] if the outside observer sees the winner's payment as compared to a situation where only the winner is revealed.

Table 2: Equilibrium predictions per treatment

\begin{tabular}{|c|c|c|c|c|}
\hline Treatment & Auction & $\begin{array}{l}\text { Information to the } \\
\text { outside observer }\end{array}$ & Equilibrium bids & $\begin{array}{l}\text { Expected } \\
\text { revenue }\end{array}$ \\
\hline FPW & FP & The winner & $B(v) \approx \frac{2}{3} v+22$ & $R \approx 72$ \\
\hline FPWP & FP & $\begin{array}{c}\text { The winner and her } \\
\text { payment }\end{array}$ & $B(v)=v$ & $R=75$ \\
\hline SPW & SP & The winner & $B(v) \approx v+22$ & $R \approx 72$ \\
\hline SPWP & SP & $\begin{array}{c}\text { The winner and her } \\
\text { payment }\end{array}$ & $B(v)=\frac{v}{2}+62.5$ & $R=87.5$ \\
\hline FPW control & FP & The winner & $B(v)=\frac{2}{3} v$ & $R=50$ \\
\hline $\begin{array}{l}\text { FPWP } \\
\text { control }\end{array}$ & FP & $\begin{array}{c}\text { The winner and her } \\
\text { payment }\end{array}$ & $B(v)=\frac{2}{3} v$ & $R=50$ \\
\hline SPW control & SP & The winner & $B(v)=v$ & $R=50$ \\
\hline $\begin{array}{l}\text { SPWP } \\
\text { control }\end{array}$ & SP & $\begin{array}{c}\text { The winner and her } \\
\text { payment }\end{array}$ & $B(v)=v$ & $R=50$ \\
\hline
\end{tabular}

Notes: Equilibrium bids in the unique symmetric D1 equilibrium for bidder values $v$ being independently drawn from $U[0,100]$, and the expected revenue of the auction in this equilibrium. 
In SPWP, the winner's payment reveals the valuation of the second highest bidder in the fully separating equilibrium, but the outside observer cannot deduce which losing bidder made the second highest bid. The difference between winning and losing is - in terms of the outside observer's estimate - very large for a low-value bidder. If he wins [loses], the outside observer optimally estimates his value to be the average between the second highest value and 100 [3/4 of the second highest value]. This leads a low-value bidder to submit a considerably higher bid when the outside observer obtains information about the winner's payment. In Online Appendix B, we formally derive the equilibrium bidding strategies. These are presented in Table 2.

The theoretical predictions regarding the auction's revenue and bidding behaviour yield the following hypotheses which we will test using our experimental design:

Hypothesis 1 In the FP auction, revealing both the winner and his payment to the outside observer increases the average auction revenue as compared to a setting where only the auction winner is revealed.

Hypothesis 2 In the SP auction, revealing both the winner and his payment to the outside observer increases the average auction revenue as compared to a setting where only the auction winner is revealed.

Hypothesis 3 In the setting where both the winner and his payment are revealed to the outside observer, the average auction revenue is higher in the SP auction than in the FP auction.

Hypothesis 4 In the setting where only the winner is revealed to the outside observer, the FP auction and the SP auction yield the same revenue, on average.

\section{Results}

In this section, we present our experimental results. We start in subsection 4.1 by comparing the auction revenue between treatments. In subsection 4.2 , we analyse bidding behaviour. In subsection 4.3, we discuss the outside observer's estimates and their effect on bids. Finally, in subsection 4.4, we present an efficiency comparison between auctions. Concerning the statistical analysis, two-sided Mann-Whitney U tests are employed in the case of non-parametric analysis, using groups as single observations. The parametric analyses are based on ordinary least-square regressions, where standard errors are clustered by group. Unless stated otherwise, the results refer to the main treatments, i.e., where the outside observers' estimates affect bidders' payoffs. 


\subsection{Auction revenue}

In this subsection, we explore the effect of the auction type and the information revealed to the outside observer on auction revenue. Figure 1 shows the average auction revenue for each of the treatments. The FP auction where both the winner and his payment are communicated to the outside observer yields the highest revenue on average; average auction revenue is significantly higher in FPWP than in the other non-control treatments ( $p=0.08, p=0.00$, and $p=0.04$ for FPW, SPWP, and SPW, respectively). In particular, in the FP auction, revealing the winner and his payment increases the auction's revenue, on average, by almost 7 units as compared to the case where only the winner is revealed. The increase in revenues is even greater when comparing FPWP with both SP treatments. A parametric analysis, where the highest valuation is included as a control variable, confirms this result (see Table 3). Figure 2 represents the regression results graphically. The revenue estimates are higher in FPWP than in any of the other treatments for all highest values above 20 (i.e., for $98 \%$ of the realizations of the highest values).

Figure 1: Average auction revenue by treatment

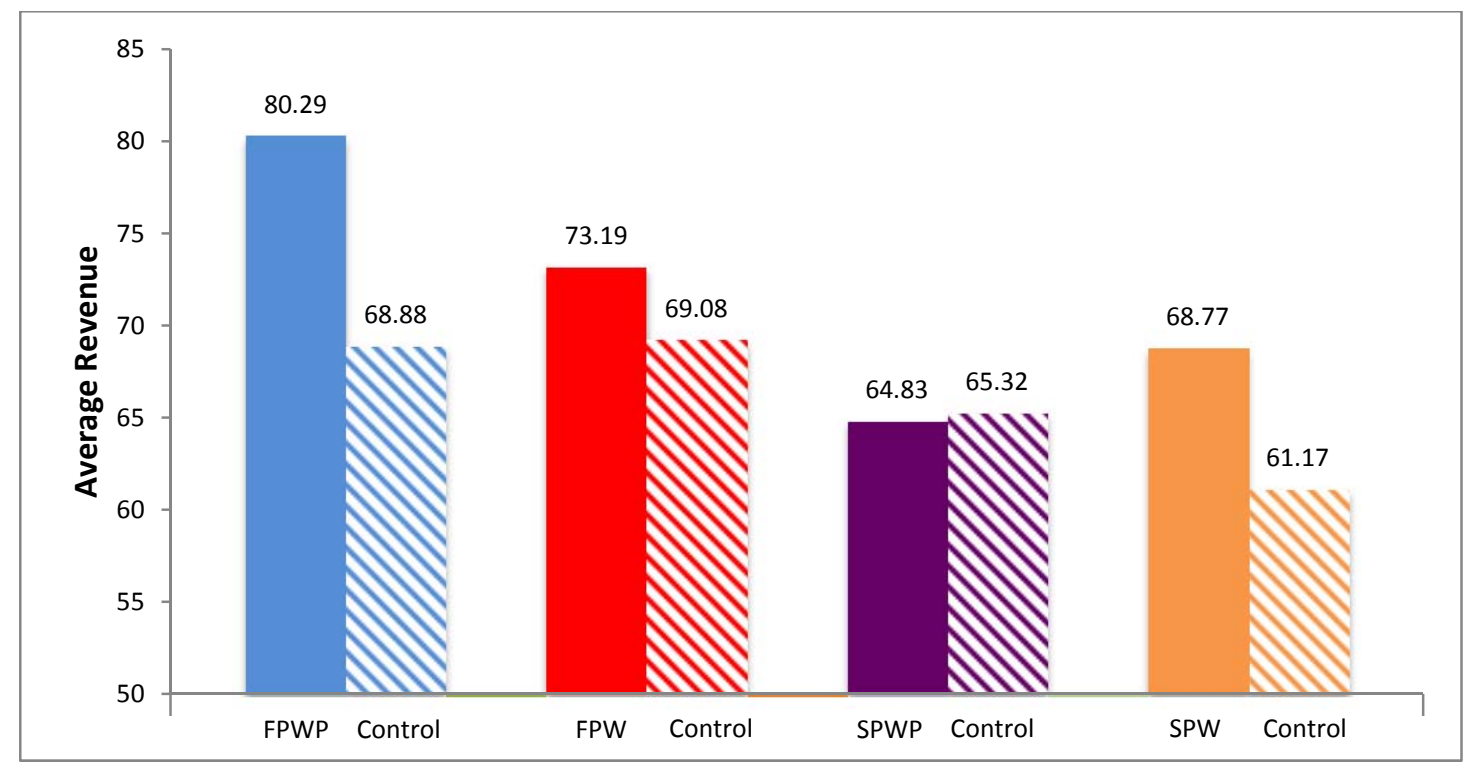

Due to the fact that the FP auction generally yields more revenue in the lab than the SP auction does, ${ }^{10}$ we check for the robustness of our findings in a difference-in-difference analysis where we compare the revenues in the main treatments, correcting for the revenues obtained in the control treatments. We do so by running a linear regression of revenue on treatment dummies. Table 4 reports the estimated differences between the treatments and the corresponding p-values.

10 See Kagel (1995) for an overview. 
Table 3: Auction revenue per treatment controlling for the highest value

\begin{tabular}{lcc}
\hline & Revenue (1) & Revenue (2) \\
\hline Intercept & $-5.8736(3.3687)$ & $10.0810(2.4631)^{* * *}$ \\
HighestValue & $0.9891(0.0499)^{* * *}$ & $0.7847(0.0268)^{* * *}$ \\
FPWP & $7.1048(2.2286)^{* *}$ & $-5.2341(8.7926)$ \\
SPWP & $-8.3524(2.0827)^{* * *}$ & $-27.8704(7.5080)^{* * *}$ \\
SPW & $-4.4095(3.3687)$ & $-36,3713(6,8149)^{* * *}$ \\
HighestValue ${ }^{*}$ FPWP & & $0.1543(0.1318)$ \\
HighestValue $^{*}$ SPWP & & $0.2442(0.0923)^{* *}$ \\
HighestValue $^{*}$ SPW & & $0.3999(2.4631)^{* * *}$ \\
\hline$N$ & \multicolumn{3}{c}{} \\
\hline
\end{tabular}

Notes: Clustered standard errors in parentheses. FPW is the reference treatment. HighestValue denotes the highest value among the three bidders. FPWP raises significantly higher revenue than SPW and SPWP $(\mathrm{p}<0.01)$. SPWP and SPW do not differ significantly from each other in terms of revenue raised at the $90 \%$ level. ${ }^{*} \mathrm{p}<0.1,{ }^{* *} \mathrm{p}<0.05,{ }^{* * *} \mathrm{p}<0.01$.

Figure 2: Revenue estimates as a function of the highest value in a bidder group per treatment

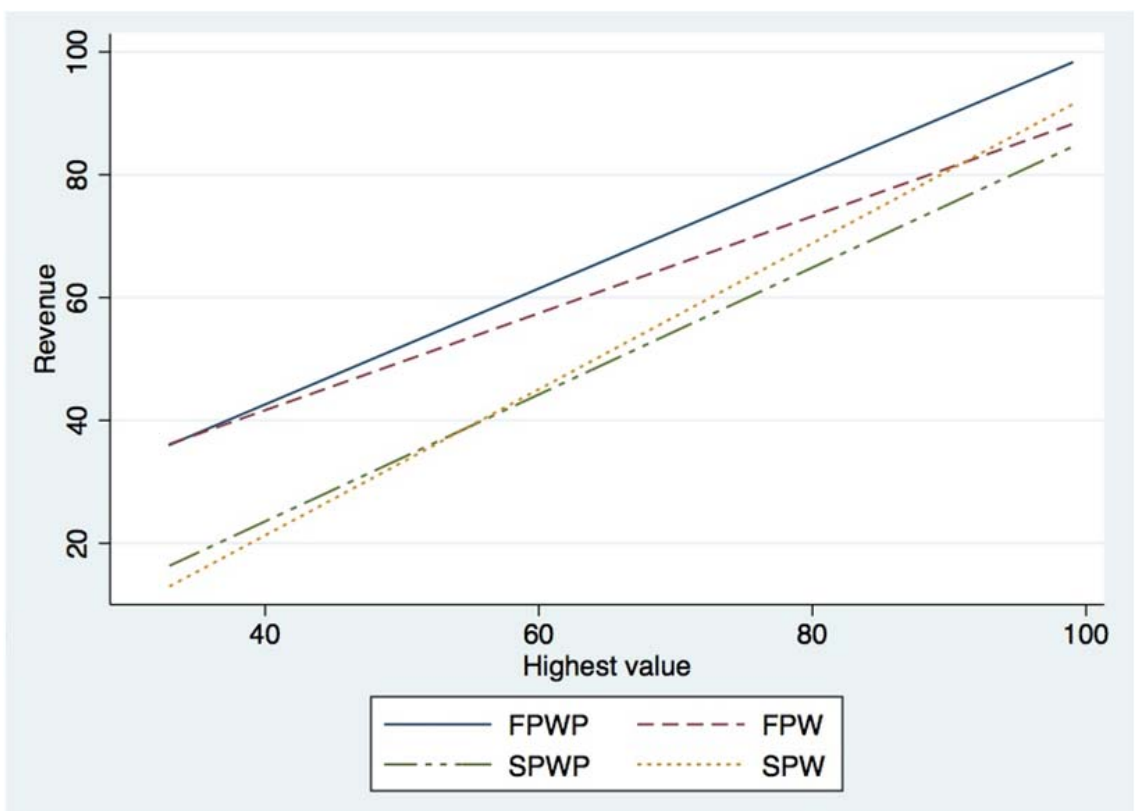

Note: The curves are based on the linear regression estimates reported in Table 3. 
Table 4: Difference in auction revenue between treatments relative to the corresponding control treatments

\begin{tabular}{lccc}
\hline & $F P W P$ & $S P W P$ & $S P W$ \\
\hline$F P W$ & $-7.29^{* * *}(\mathrm{p}=0.01)$ & $4.60(\mathrm{p}=0.23)$ & $-3.50(\mathrm{p}=0.39)$ \\
$F P W P$ & - & $11.89^{* *}(\mathrm{p}=0.02)$ & $3.79(\mathrm{p}=0.26)$ \\
$S P W P$ & & - & $-8.00^{*}(\mathrm{p}=0.06)$ \\
\hline
\end{tabular}

Notes: The numbers reported are the differences between the treatment in the row and the one in the column in terms of the revenue differences between main treatment and control treatment. ${ }^{*} \mathrm{p}<0.1$, ${ }^{* *} \mathrm{p}<0.05,{ }^{* * *} \mathrm{p}<0.01$

Result 1: In the FP auction, revealing both the winner and his payment significantly increases revenue for the auctioneer as compared to the case where only the winner is revealed.

This result confirms hypothesis 1 . The FPWP treatment yields higher revenues for the auctioneer than the FPW treatment does. This means that in the FP auction, the auctioneer can increase her revenue by publishing the auction's winning bid, rather than publishing the winner only.

Regarding the SP auction, there are no significant differences between SPWP and SPW treatments $(\mathrm{p}=0.41)$.

Result 2: In the SP auction, revealing both the winner and his payment does not significantly increase auction revenue as compared to the case where only the winner is revealed. In a difference-in-difference analysis, revealing the winner's payment yields significantly lower revenue.

This result contradicts hypothesis 2 . The availability of more information increases the auctioneer's revenue in the FP auction, but not in the SP auction. The driving force behind this result may be that the accuracy of the outside observers' estimates of bidders' values is higher in FPWP compared to FPW, but not in SPWP compared to SPW, as we will show in subsection 4.4 .

Result 3: When both the winner and his payment are revealed, the FP auction raises significantly more money than the SP auction does.

Result 3 contradicts hypothesis 3 . Again, the outside observers' accuracy, and how bidders respond to differences in value estimates for winners and losers, may explain this result. The analysis of bidding behaviour in subsection 4.2 sheds more light on this discrepancy between the experimental results and the theoretical predictions.

Comparing FP and SP auctions where only the winner is revealed, the average revenue is 3.53 points higher in FPW than in SPW, but not significantly different $(p=0.18)$. 
Result 4: When only the winner is revealed, FP and SP auctions do not differ significantly in terms of average auction revenue.

This result is in line with hypothesis 4 . The observed average revenues for FPW and SPW are also not far from the theoretical predictions.

\subsection{Bidding behaviour}

In this subsection, we analyse the subjects' bidding behaviour to discover the extent to which it is in line with the theoretical predictions and, if not, how it contributes to the rejection of some of our hypotheses in the previous subsection. Table C.1 in Online Appendix $\mathrm{C}$ includes scatter plots which contrast bids submitted with the theoretical predictions.

We start by exploring how bidding strategies depend on whether the outside observer influences bidders' payoffs. Figure 3 shows average bids per treatment. For all auctions, and for all values greater than zero, equilibrium bids are, on average, higher if the outside observer's estimates affect bidders' payoffs. In the FP auction, when outside observers' estimates affect bidders' payoffs, bidders bid more aggressively when compared to the treatments where their payoffs only depends on the outcome of the auction ( $\mathrm{p}=0.00$ and $\mathrm{p}=0.07$ for FPWP and FPW, respectively). In the SP auction, average bids are higher than in the control treatments, although the difference is only statistically significant in SPW and not in SPWP ( $p=0.06$ and $p=0.57$, respectively). ${ }^{11}$ By and large, average bidders' responses are consistent with the equilibrium logic in all treatments.

In the main treatments, revealing the winner and his payment increases average bids significantly in the FP auction as compared to the case when only the winner is revealed $(\mathrm{p}=0.04)$. In contrast, no significant differences between bids are found in the SP auction when the information revealed to the outside observer is modified $(p=0.95)$. Perhaps not surprisingly, these observations are in line with the observed treatment differences in terms of revenue.

\footnotetext{
${ }^{11}$ A potential explanation of the latter observation is the high frequency of extreme overbidding compared to the weakly dominant strategy of bidding value in SPWPcontrol (see Table C.1 in Online Appendix C).
} 
Figure 3: Average bids in FP and SP auctions

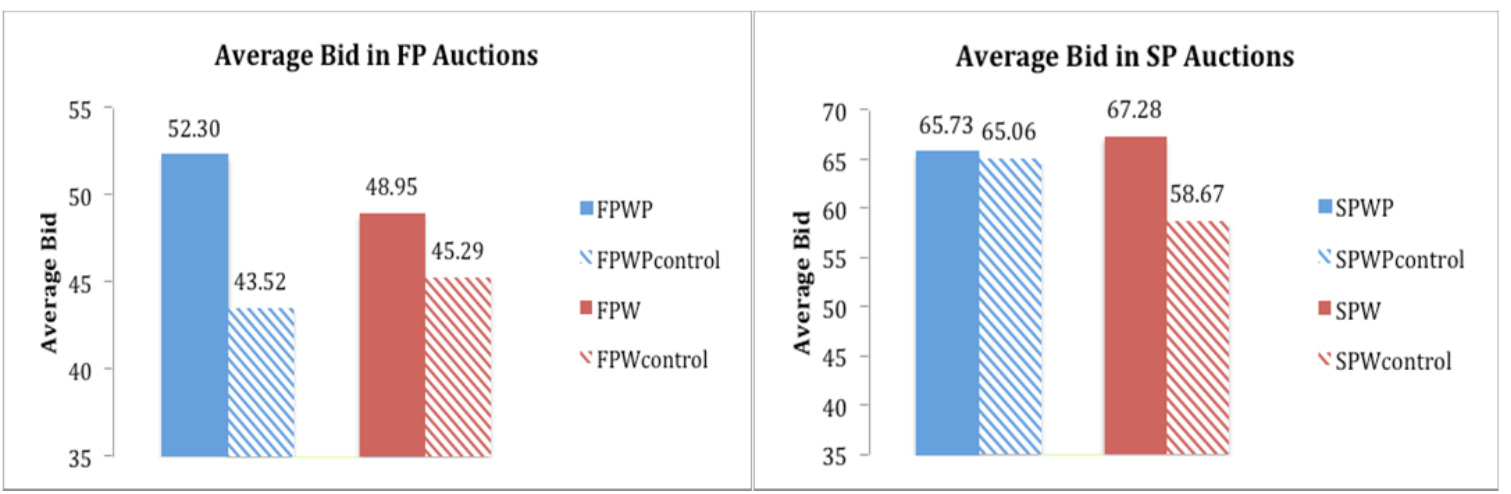

We now turn to analysing bidding behaviour in the FP auction. Table 5 presents estimated bidding functions, and Figure 4 contrasts these with the equilibrium bidding curves in Table 2. Bids in FPWP diverge from the theoretical predictions to some extent. The intercept is significantly greater $(p<0.01)$ and the slope is less steep $(p=0.03)$ than the theoretical prediction. As a consequence, low-value bidders submit higher bids than in equilibrium, while high-value bidders submit slightly lower bids. On average, bidders behave similar to the predictions. ${ }^{12}$ For FPW, the estimated bidding curve lies below the theoretical prediction $(\mathrm{p}=0.03$ and $\mathrm{p}=0.02$ for the differences in slope and intercept, respectively, between the observed bids and the theoretical prediction) for low and intermediate values. As the scatter plot in Online Appendix C indicates, it is mainly subjects with low and intermediate values who underbid. Notice that equilibrium bidding entails bids above value for values below 66 . Subjects seem to be hesitant about submitting bids above their value; in the case that value is lower than 66 , about $70 \%$ of the bids are actually below value. In contrast with the main treatments, subjects bid more aggressively in the control treatments than in the equilibrium prediction, not less. This is in line with what is generally observed in the FP auction in the lab. ${ }^{13}$

Result 5 summarizes the main findings for bidding behaviour in the FP auction.

Result 5: In the FP auction, compared to the control treatments, bidders bid more aggressively when the outside observer's estimates affect their payoffs. Bidders in FPW tend to underbid relative to the equilibrium prediction, particularly for low and intermediate values. In FPWP, bidders overbid for low values and underbid for high values.

We now turn to the SP auction. Figure 5 displays estimated bidding functions based on the regressions reported in Table 6 . In both treatments, bidders tend to significantly underbid relative to the equilibrium predictions. In SPWP, low-value bidders in particular bid substantially lower than the equilibrium prediction $(\mathrm{p}<0.01$ for the

\footnotetext{
${ }^{12}$ See Table C.1. in Appendix C.

${ }^{13}$ See, e.g., Cox et al. (1988); Harrison (1989); Kagel (1995); and Goeree et al. (2002).
} 
differences between the observed bids and the theoretical prediction for both the slope and the intercept). They seem to feel hesitant to bid as much as 62.5 points above their value. In SPW, bidders underbid on average over the entire value range $(p=0.45$ and $\mathrm{p}=0.01$ for the differences in slope and intercept respectively between the observed bids and the theoretical prediction). Bidders bid 22 points above their value according to the equilibrium prediction. Again, subjects are hesitant to submit bids which are significantly greater than their values, as the scatter plot in Online Appendix $\mathrm{C}$ shows. Only $63 \%$ of the bids are above value, and the majority of these are in between value and value plus 22 .

Table 5: Estimated bidding function for the FP auction

\begin{tabular}{lcc}
\hline & Bid & Theoretical prediction \\
\hline Intercept & $6.2476^{*}(2.8823)$ & 22 \\
Value & $0.8048^{* * *}(0.0481)$ & $2 / 3$ \\
FPWP & $2.1628^{*}(1.0733)$ & -22 \\
FPWPcontrol & $-6.0022^{* *}(2.7355)$ & -22 \\
FPWcontrol & $-5.9411^{*}(2.6659)$ & -22 \\
Value*FPWP & $0.0224(0.0444)$ & $1 / 3$ \\
Value*FPWPcontrol & $0.0118(0.0687)$ & 0 \\
Value*FPWcontrol & $0.0441(0.0485)$ & 0 \\
\hline$N$ & 2518 & \\
\hline
\end{tabular}

Notes: Clustered standard errors in parentheses. FPW is the reference treatment. ${ }^{*} \mathrm{p}<0.1,{ }^{* *} \mathrm{p}<0.05$, *** $\mathrm{p}<0.01$.

Figure 4: Estimated bidding functions vs. theoretical predictions for the FP auction
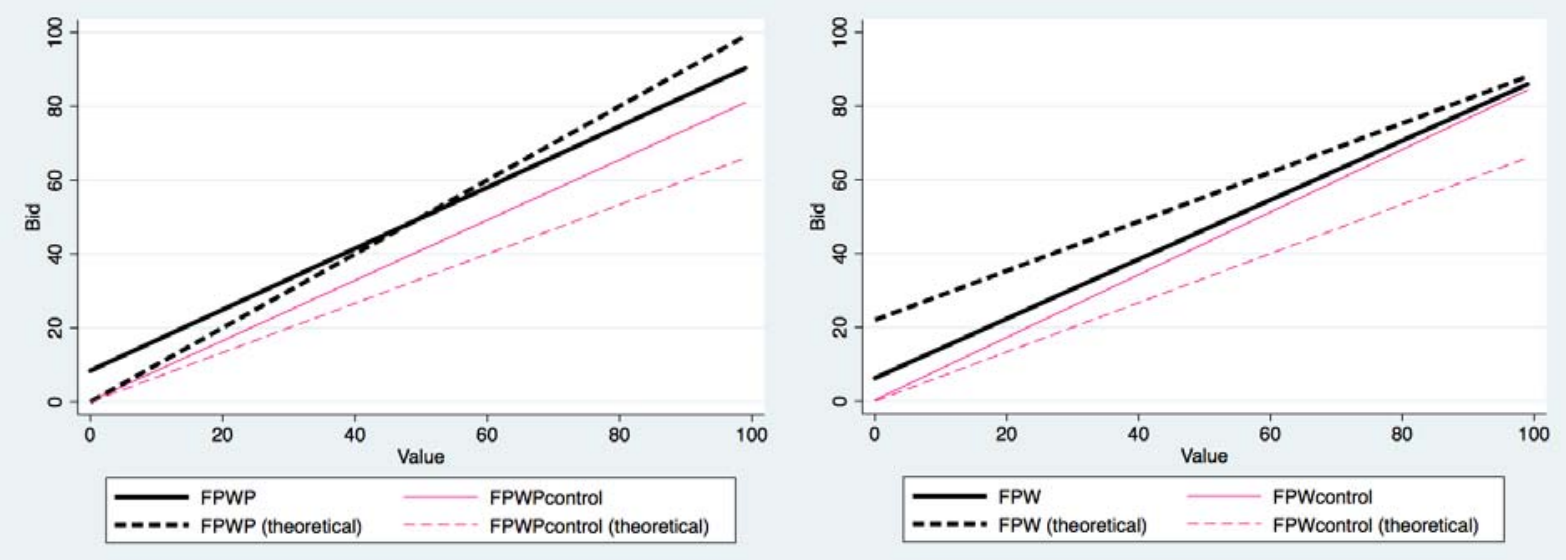

Note: The solid lines are estimates based on the linear regression estimates reported in Table 4. The dashed lines refer to the theoretical predictions in Table 2 .

Result 6: In SPW, the average bid is significantly higher than in the control treatment. Bidders tend to underbid as compared to the equilibrium prediction. 
Result 7: In SPWP, the average bid is not significantly higher than in the control treatment. Bidders tend to underbid as compared to the equilibrium prediction, particularly bidders with low values.

Table 6: Estimated bidding functions for the SP auction

\begin{tabular}{lcc}
\hline & Bid & Theoretical prediction \\
\hline Intercept & $11.4418^{* * *}(2.6629)$ & 22 \\
Value & $1.0526^{* * *}(0.06521)$ & 1 \\
SPWP & $8.0788^{* *}(3.1726)$ & 40.5 \\
SPWPcontrol & $-3.3336(4.8040)$ & -22 \\
SPWcontrol & $-9.2593^{* *}(2.8356)$ & -22 \\
Value*SPWP & $-0.1781^{* *}(0.0664)$ & $-1 / 2$ \\
Value*SPWPcontrol & $0.0251(0.0553)$ & 0 \\
Value*SPWcontrol & $0.0122(0.0966)$ & 0 \\
\hline$N$ & 2509 & \\
\hline
\end{tabular}

Notes: Clustered standard errors in parentheses. SPW is the reference treatment. ${ }^{*} \mathrm{p}<0.1,{ }^{* *} \mathrm{p}<0.05$, $* * * \mathrm{p}<0.01$.

Figure 5: Estimated bidding functions vs. theoretical predictions for the SP auction
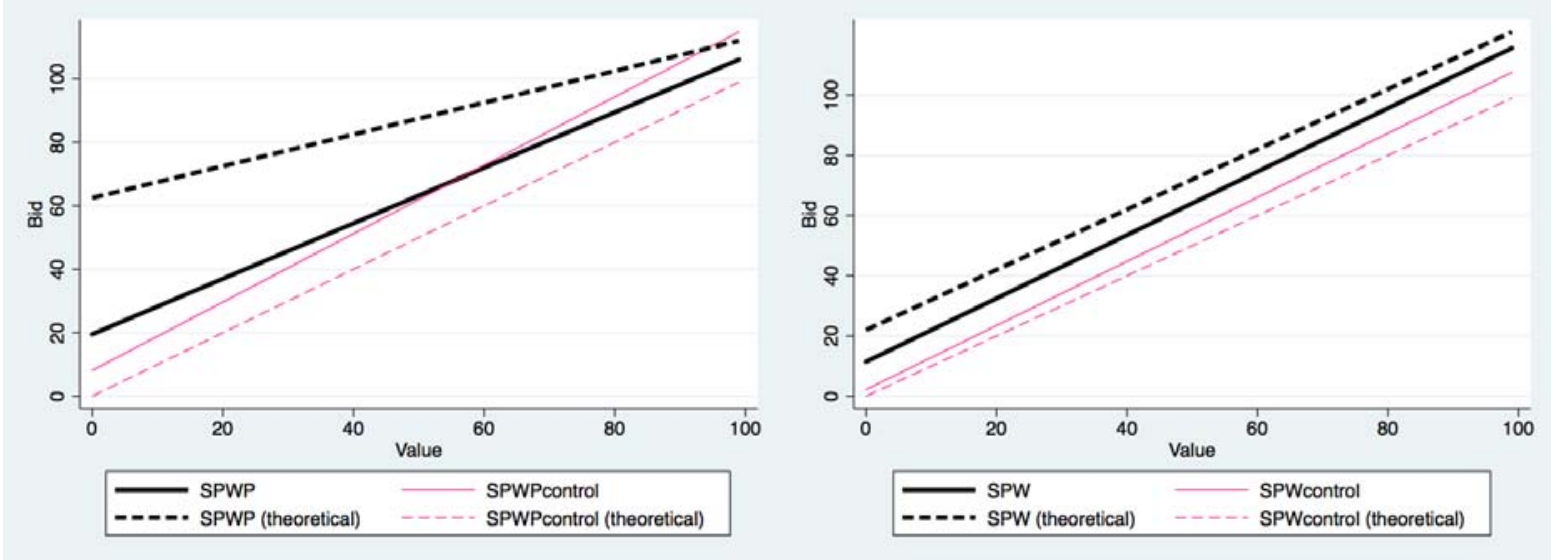

In all treatments, underbidding relative to equilibrium is most prominent in SPWP. This is likely the case because bidders feel hesitant to bid substantially more than their value as the equilibrium prediction dictates. Moreover, the high bids of low-value bidders in the equilibrium prediction crucially depend on the outside observer making the correct inferences. In the next subsection, we shall see that the observed outside observer's estimates are systematically biased, and that this is particularly the case for SPWP in the case of low payments by the winner. As a result, revenue in SPWP is not greater than in FPWP or SPW, in contrast to hypotheses 2 and 3. 
Finally, bidding functions in SPWP and SPW are compared. Even though average bids do not differ between both treatments, the bidding functions differ significantly from each other. In particular, low-value bidders place higher bids in SPWP than in SPW (the intercept is significantly higher in SPWP). This result is reversed for high-value bidders (bidding function is significantly steeper in SPW). As such, these findings are qualitatively in line with the theoretical predictions.

\subsection{Outside observers' estimates and their effect on bids}

In the previous subsection, we observed that bids in FPWP are close to equilibrium, on average. While in the other treatments, we observe consistent underbidding. Much of the underbidding is explained by bidders relying on bids which are close to their values, while equilibrium sometimes requires substantial overbidding.

In this subsection, we explore the extent to which the outside observers' behaviour drives these bidding patterns. Bidding above value is optimal in equilibrium because winning the auction implies an additional reward in terms of the outside observer's inference. In the experiment, this particular reward depends on the actual behaviour of the subject in the role of the outside observer. We first analyse how the types of auctions, and the different elements of information provided to the outside observer, influence her estimates of the bidders' values. We then analyse how these estimates affect bidding behaviour. In particular, we conjecture two mechanisms through which the outside observer can affect bidding strategies: first, the difference in the outside observers' estimates for winners and losers may differ between treatments or among groups, and this may influence bidding behaviour. Second, the accuracy of the outside observer's estimates may also have an effect on the bids.

Figures C.2 and C.3 in Online Appendix C contrast the value estimates of the outside observers and the actual values, for winners, for losers, and for the difference between winners and losers, considering different winners' payments and all main treatments. When outside observers are only informed about the identity of the winner, their guesses cannot depend on the winner's payment. Therefore, by construction, estimates for winners and losers do not depend on the winner's payment in FPW and SPW. In addition, in both types of auctions, outside observers underestimate winners' values and overestimate losers' values on average. As a consequence, in both FPW and SPW, the differences between the value of the winners and the value of the losers are underestimated, such that the additional benefit for the winning bidder is smaller than in the theoretical prediction. In particular, on average, the estimated difference between the value of the winner and the value of the loser is 20.63 and 23.62 for FPW and SPW, respectively. These do not differ significantly $(p=0.95)$. The bidders' best response is to inflate their bids relative to the control treatments by half that difference, i.e., by 10.32 and 11.81 points in FPW and SPW, respectively. According to the data, bidders inflate their bids with respect to the controls by 3.66 and 8.61 points on average in FPW and 
SPW, respectively (see Figure 3). Overbidding is slightly lower than expected, but it is close to, and qualitatively in line with, the theoretical predictions.

In FPWP and SPWP, the outside observers can adjust their estimates for winners and losers depending on the information received regarding the winner's payment (the highest bid in FPWP and the second highest bid in SPWP). Figures C.2 and C.3 in Online Appendix $C$ show that the estimates for the values of both the winners and the losers increase with the winners' payment in both FPWP and SPWP $(p<0.02)$. Similarly, in auctions where only the winner is revealed, the outside observers generally underestimate the winners' values, and overestimate the losers' values. On average, the difference between the estimated value of the winner and the value of the loser is 23.21 and 18.42 for FPWP and SPWP, respectively. These numbers do not significantly differ between both auctions, and in fact, they do not differ significantly between the four treatments.

The difference in estimates, conditional on the winner's payment, does differ significantly between auctions. The empirical differences between the outside observers' estimates of the winners' and losers' value are plotted in Tables C.2 and C.3 in Online Appendix C. Figure 6 includes results from linear regressions of the actual differences in the winner's payment. In theory, the difference between the outside observer's estimates of the winners' and losers' value increases with the winner's payment in the FPWP and decreases with the winner's payment in the SPWP. In line with the theory, the difference significantly increases with respect to the winner's payment in the FPWP ( $\mathrm{p}=0.02)$, albeit to a lesser extent than theoretically predicted. In contrast, the difference between estimates for winners and losers does not depend in a statistically meaningful way on the winner's payments in the SPWP $(p=0.95)$. This suggests a possible explanation for the fact that the low-value bidders, especially, underbid in comparison to the theoretical prediction in the SPWP, and that the observed behaviour does not corroborate hypothesis 3 .

Result 8: The outside observers generally underestimate the value of the winners and overestimate the value of the losers. As a consequence, the difference between the winner's and the losers' value is underestimated in all treatments. 
Figure 6: Differences in the outside observer's value estimates between winners and losers
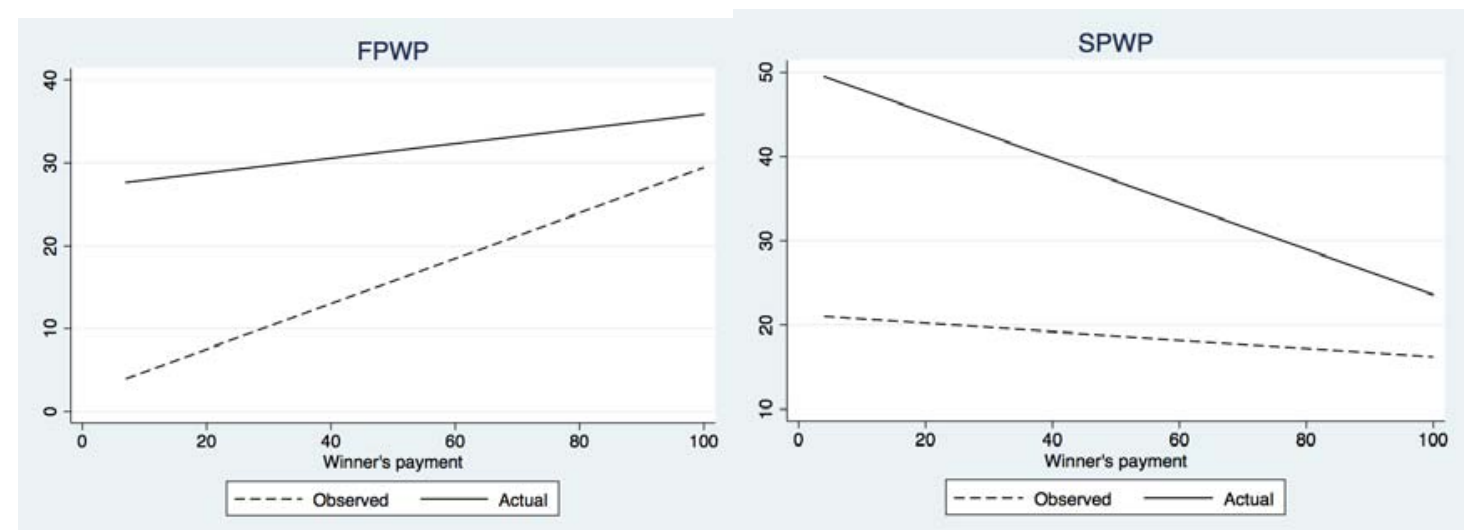

Notes: The figure plots the results of linear regressions of the observed differences between the outside observer's value estimates for the winners and the losers (dashed line) as well as the actual differences between winners' and losers' values on the winner's payment.

\subsection{Efficiency}

In this subsection, we undertake an efficiency analysis to determine which combination of auction and information scenario yields the highest average aggregate payoffs for all parties that participate in our setting. For a given group and auction type, the efficiency in period $t$ comprises the sum of three terms:

$$
\text { Efficiency }_{t}=\text { ValueWinner }_{t}+\text { EarningsOO }_{t}+\frac{1}{2} \sum_{i=1}^{3} \text { Estimate }_{i t}
$$

where ValueWinner $_{t}$ is the value of the winner of the auction at period $t$, EarningsOO are the earnings of the outside observer at period $t$, and Estimate $_{i t}$ is the outside observer's estimate of bidder $i$ at period $t$. ValueWinner $r_{t}$ measures the auction's efficiency in terms of allocating the object. The second term in the expression above measures the payoffs of the outside observer. The last term measures the sum of the payoffs obtained by the three bidders through the estimates from the outside observer. Efficiency does not depend on the auction's revenue (it is a welfare-neutral transaction between a bidder and the auctioneer). Figure 11 compares the average value of each term and the overall average efficiency between treatments.

The average value of the winner in the auction is the highest in the FPW treatment ( $p=0.06, p=0.06$ and $p=0.08$ with respect to FPWP, SPWP and SPW respectively). The average value of the winner is not significantly different when compared to the other treatments. This means that the FP auction where only the winner is revealed allocates the good in the most efficient way among the bidders. In other words, even though 
revealing the winner's payment in the FP auction increases average earnings for the auctioneer, it reduces the allocative efficiency of the auction.

Figure 11: Efficiency comparison between treatments.
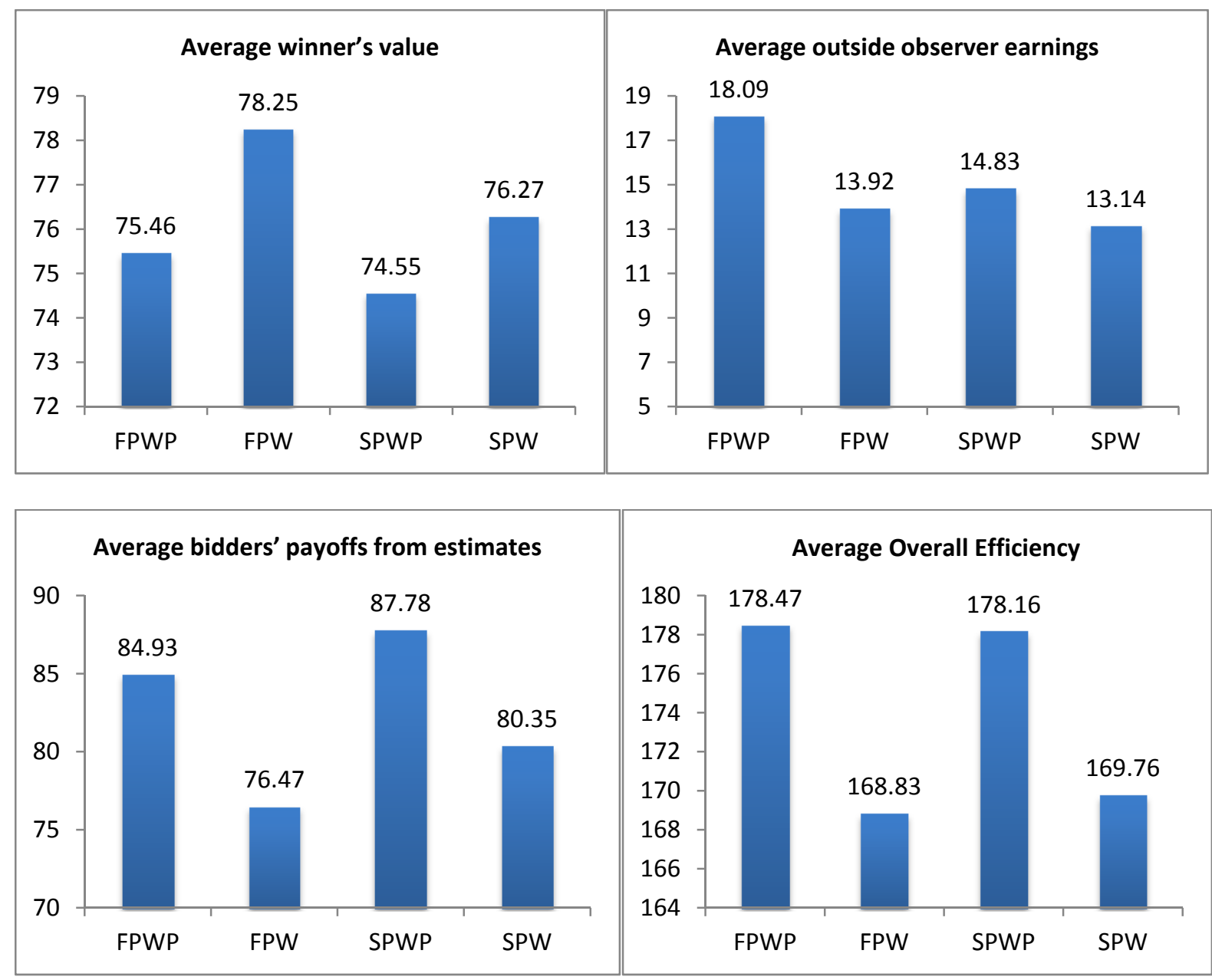

Table 7: Allocative efficiency

\begin{tabular}{l|cccc}
\hline Treatment & $\begin{array}{c}\text { \% highest } \\
\text { value wins }\end{array}$ & $\begin{array}{c}\text { Difference } \\
\text { with FPW }\end{array}$ & Value winner/Highest value & $\begin{array}{c}\text { Difference } \\
\text { with FPW }\end{array}$ \\
\hline FPW & $83.3 \%$ & & $97.5 \%$ & \\
FPWP & $71.9 \%$ & $-11.43 \%^{* * *}$ & $93.9 \%$ & $-3.68 \%^{* *}$ \\
SPW & $76.7 \%$ & $-6.67 \%$ & $95.2 \%$ & $-2.34 \%$ \\
SPWP & $76.2 \%$ & $-7.14 \%^{*}$ & $92.7 \%$ & $-4.84 \%^{* * *}$ \\
\hline
\end{tabular}

Notes: ${ }^{*} \mathrm{p}<0.1,{ }^{* *} \mathrm{p}<0.05,{ }^{* * *} \mathrm{p}<0.01$

Table 7 presents two other measures of allocative efficiency. The first measure shows the percentage of auctions in which the bidder with the highest valuation wins for each treatment. The second measure is the average ratio of the value of the winning bidder 
over the value of the bidder with the highest value. According to both measures, allocative efficiency varies significantly across treatments. In particular, efficiency in FPWP is significantly lower than in FPW. Note that the allocative efficiency in both WP treatments is also clearly lower than the usual efficiency levels in the literature. ${ }^{14}$

The outside observer's average earnings are significantly higher in FPWP as compared to FPW, SPWP, and SPW $(p=0.04, p=0.02, p=0.02$, respectively). No significant differences in outside observer's earnings are found between the other three treatments. This means that the outside observer has the highest accuracy in estimating bidders' values in the FP auction where both the winner and his payment are revealed. Revealing the winning payment helps outside observers to increase the accuracy of their estimates in the FP auction, but it does not help in the SP auction. A possible explanation for this is that revealing the winner's payment gives different information to the outside observers in the FP auction than in the SP auction. The winning payment represents the own bid of the winner in the FP auction, but it only represents the second highest bid in the SP auction. Hence, the winner's payment allows the outside observer to theoretically pinpoint the value of at least one bidder with certainly in the FP auction. While, on the other hand, no bidder can be fully identified in the SP auction.

We find that in FPWP and SPWP, bidders obtain significantly higher payoffs from the outside observer's estimates than in FPW and SPW, respectively $(p=0.01$ and $p=0.06$ respectively). Therefore, revealing more information induces outside observers to increase their value estimates so that, in turn, bidders benefit more from signalling. Neither the differences between FPWP and SPWP, nor those between FPW and SPW, are statistically significant ( $\mathrm{p}=0.53$ and $\mathrm{p}=0.25$, respectively).

All in all, none of the treatments outperform the others in all three performance measures. In particular, there is a trade-off between allocative efficiency and the payoffs bidders earn from the outside observer's estimates. Total average efficiency is higher in FPWP and SPWP as compared to FPW and SPW ( $\mathrm{p}=0.03$ and $\mathrm{p}=0.03$, respectively). Therefore, more information increases overall average efficiency in both FP and SP auctions. However, we should be cautious with this result because the earnings of the outside observer and the bidders are not necessarily expressed in the same monetary units.

Result 9: Allocative efficiency is significantly higher in FPW than in the other three treatments which, in turn, do not differ significantly between each other in terms of allocative efficiency. FPWP yields significantly higher bidder payoffs from the outside observer's estimates than the other treatments which, in turn, do not differ significantly regarding this outcome measure. Both bidder payoffs from the outside observer's estimates and overall efficiency are significantly higher in FPWP and SPWP than in SPW and FPW,

\footnotetext{
${ }^{14}$ See, for example, Cox et al. (1982) and Kagel and Levin (1993).
} 
respectively. When keeping the information revelation policy fixed, the two auctions do not differ significantly along those outcome measures.

\section{Conclusion}

In many auction settings, bidders have the opportunity to signal their generosity, wealth, or productivity to outside observers. The applications of this range from local charity auctions to multi-million dollar art auctions, and even to multi-billion dollar spectrum auctions. A primary-school pupil's parent may submit a high bid in the school's fundraising event to signal her generosity to other parents. A bidder in an art auction may want to signal his wealth to third parties by submitting high bids. A telecommunications firm's behaviour in a spectrum auction contains information about the quality of its management which may be a valuable signal by the firm's management to investors and the labour market. Signalling in auctions has received ample attention in recent literature. Still, our paper is the first study which compares the relative performance of commonly used auction formats in an experimental setting. In the experiment, we compared the first-price sealed-bid auction and second-price sealed-bid auctions under two information regimes: in one, the auctioneer only reveals the identity of the winner, and in the other, she also publishes the winner's payment.

Our key finding is that the first-price sealed-bid auction in which the winner's payment is revealed performs the best among the mechanisms studied in terms of revenue and overall efficiency. Moreover, revealing the winner's payment inflates the bids in the first-price auction, but it does not do so in the second-price auction. These findings are robust in that we obtain qualitatively the same results in a difference-in-difference analysis where we compare the revenues in the main treatments, correcting for the revenues obtained in control treatments. Our efficiency analysis reveals that both the outside observer and the bidders benefit from revealing the winner's payment in both auctions, albeit at the cost of allocative efficiency in the first-price auction.

Overall, our experimental results suggest that both the auction type and the amount of information revealed can have a significant impact on the auction performance, especially in a context where bidders care about how their behaviour in the auction is interpreted by others. The average revenue in the first-price sealed-bid auction, where the auctioneer reveals the winner's payment, is $10-25 \%$ higher than in the three other mechanisms studied. This finding suggests that it might be in the best interest of organizers of charity auctions, art auctions, and spectrum auctions to use first-price auctions, rather than second-price auctions, and, moreover, to reveal how much the winner pays.

A natural follow-up question concerns the extent to which our results can be extrapolated in the field. Field experiments may reveal the circumstances under which first-price auctions actually perform better than second-price auctions in settings where 
bidders have signalling opportunities. Carpenter et al. (2008) provide suggestive evidence in this direction. In a field experiment conducted during fundraising campaigns at preschools, they find that the first-price sealed-bid auction raises more money than the second-price sealed-bid auction. More generally, future experiments, both in the lab and in the field, might identify auction types as well as information revelation policies that perform even better than the ones examined in our lab experiment.

\section{References}

Andreoni J. and B.D. Bernheim (2009): "Social Image and the 50-50 Norm: A Theoretical and Experimental Analysis of Audience Effects," Econometrica, 77(5), 1607-1636.

Andreoni J., Che Y-K. and K. Jinwoo (2007): “Asymmetric Information about Rival's types in Standard Auctions: An Experiment," Games and Economic Behavior, 59(2), 240-259.

Banks, J. S. and J. Sobel (1987): “Equilibrium Selection in Signaling Games,” Econometrica, 55, 647-661.

Bos, O. and T. Truyts (2017): “Auctions with Signaling Concerns,” MPRA Paper 79181.

Brandts J. and C. Holt (1993): "Adjustment Patterns and Equilibrium Selection in Experimental Signaling Games," International Journal of Game Theory, 22(3), 279-302.

Carpenter, J., Holmes, J., and Matthews, P. H. (2008): “Charity Auctions: A Field Experiment," The Economic Journal, 118(525), 92-113.

Cason, T.N., Kannan, K.N., and Siebert, R. (2011): “An Experimental Study of Information Revelation Policies in Sequential Auctions," Management Science, 57(4), 667-688.

Cox, J., B. Roberson, and V.L. Smith. (1982): "Theory and Behavior of Single Object Auctions," in Vernon L. Smith (ed.), Research in Experimental Economics, Greenwich: JAI Press.

Das Varma, G. (2003): “Bidding for a Process Innovation under Alternative Modes of Competition," International Journal of Industrial Organization, 21(1), 15-37.

De Haan T., Offerman T. and R. Sloof (2011): “Noisy Signaling: Theory and Experiment,” Games and Economic Behavior, 73(2), 402-428.

Drouvelis M., Müller W., and A. Possajennikov (2012): “Signaling without a Common Prior: Results on Experimental Equilibrium Selection," Games and Economic Behavior, 74(1), 102-119.

Dufwenberg M. and U. Gneezy (2002): "Information Disclosure in Auctions: An Experiment," Journal of Economic Behavior \& Organization, 48(4), 431-444.

Fonseca, M.A, F. Giovannoni, and M. Makris (2016): “Auctions with External Incentives: Experimental Evidence," working paper, University of Exeter. 
Giovannoni, F. and M. Makris (2014): "Reputational Bidding," International Economic Review, 55(3), 693-710.

Goeree, J. K. (2003): "Bidding for the Future: Signaling in Auctions with an Aftermarket," Journal of Economic Theory, 108(2), 345-364.

Goeree, J. K. and T. Offerman (2002): "Efficiency in Auctions with Private and Common Values: An Experimental Study," American Economic Review, 92(3), 625-643.

Haile, P. A. (2003): “Auctions with private uncertainty and resale opportunities," Journal of Economic Theory, 108(1), 72-110.

Jeitschko, T. D. and H.-T. Normann (2012): "Signaling in Deterministic and Stochastic Settings," Journal of Economic Behavior \& Organization, 82(1), 39-55.

Kagel, J. H. (1995). Auctions: A survey of experimental research. In: J. Kagel, A. Roth, eds., The Handbook of Experimental Economics. Princeton, NJ: Princeton University Press.

Kagel, J. H and D. Levin (1993): "Independent Private Value Auctions: Bidder Behavior in First-, Second and Third-Price Auctions with Varying numbers of Bidders," Economic Journal, 103(419), 868-879.

Katzman, B. E. and M. Rhodes-Kropf (2008): “The Consequences of Information Revealed in Auctions," Applied Economics Research Bulletin, 2, 53-87.

Krishna, V. (2009): Auction Theory, Academic Press.

Liu, T. (2012): “Takeover Bidding with Signaling Incentives," Review of Financial Studies, 25(2), 522-556.

Mandel, B. R. (2009): “Art as an Investment and Conspicuous Consumption Good,” American Economic Review, 99(4), 1653-1663.

Marinovic, I. (2014): "Delegated Bidding and the Allocative Effects of Alternative Accounting Rules," mimeo.

Neugebauer, T. and R. Selten (2006): "Individual Behavior of First-price Auctions: The Importance of Information feedback in Computerized Experimental Markets," Games and Economic Behavior, 54(1), 183-204.

Schram, A. J. H. C. and Onderstal, S. (2009): "Bidding to Give: An Experimental Comparison of Auctions for Charity," International Economic Review, 50(2), 431-457.

Turocy T.L. (2009): “Covering Your Posterior: Teaching Signaling Games Using Classroom Experiments,” The Journal of Economic Education, 40(2), 188-199. 


\title{
Online Appendix A: Instructions for treatment FPWP
}

\author{
WELCOME
}

You are about to participate in an economic experiment. The instructions are simple. If you follow them carefully, you may make a substantial amount of money. Your earnings will be paid to you in euros at the end of the experiment. This will be done confidentially, one participant at a time.

Earnings in the experiment will be denoted by 'francs'. At the end of the experiment, francs will be exchanged for euros. The exchange rate is 1 euro for every 70 francs. Your starting capital equals 490 francs (or 7 euros).

These instructions consist of seven pages like this. You may page back and forth by using your mouse to click on 'previous page' or 'next page' at the bottom of your screen. At the bottom of your screen, you will see the button 'ready'. You can click this when you have completely finished with all pages of the instructions.

\section{AUCTION}

In today's experiment, you will participate in auctions. In these auctions, three bidders bid to obtain a fictitious good. The bidders are observed by an outside observer. In the remainder of these instructions we will explain the way in which the auction is organized and the rules you must follow.

\section{ROUNDS}

Today's experiment consists of 30 rounds. In each round, a fictitious good is auctioned.

In the experiment, you will be member of a group. This group consists of you and three other participants. It is unknown to you and to the other participants who is in which group. The four group members remain in the same group throughout the experiment. Thus, you will meet the same three participants in each of the 30 rounds.

In every round, one group member is randomly chosen by the computer to play the role of outside observer. The remaining three group members are the bidders in the auction.

\section{THE VALUE OF THE AUCTIONED GOOD}

The value of the fictitious good will typically differ from one bidder to the next. To be more precise, in every round, the computer will draw a new value for every bidder. Values are drawn from the set $\{1,2,3, \ldots, 100\}$.

Note the following about the value for the objects:

1. The value for a bidder is determined independently of the values for the other two bidders;

2. Any value in the set $\{1,2,3, \ldots, 100\}$ is equally likely;

3. Each bidder only learns her own value, not the value of the other bidders;

4. The outside observer is not informed about the values of any of the three bidders. 


\section{THE AUCTION}

In the auction, each of the three bidders independently submit a bid for the fictitious good. Bids must be chosen from the set $\{0,1,2, \ldots, 200\}$. The bidder with the highest bid gets the good and pays his bid. If two or three bidders submit the same (highest) bid, the computer will randomly determine which one obtains the good.

\section{THE OUTSIDE OBSERVER}

After the auction, the participant playing the role of outside observer is asked to guess the values of each of the three bidders. Before she does so, she obtains information about the outcome of the auction. In particular, she is informed about which bidder won the auction and how much the winner paid.

The payoffs of the outside observer depend on the precision of her estimates. Once she has entered value estimates for all bidders, the computer draws one of the three bidders at random. If the outside observer's estimate for this bidder is exactly correct, she obtains 40 points. The further her estimate is away from the actual value, the lower is her payoff. Specifically, if her estimate deviates $x$ points for the actual value, her payoff is equal to $40-x$. In words: the outside observer loses one point for every unit her estimate is further away from the actual value.

\section{EARNINGS FOR THE BIDDERS}

The payoffs for the bidders are dependent on both the outcome of the auction and the estimate of the outside observer.

If a bidder does not win the object, his earnings in a round only depend on the value the outside observer estimated this bidder to have:

(Earnings) $=($ The outside observer's value estimate $) / 2$

So, a bidder earns half a franc for every franc in the outside observer's value estimate. A bidder's earnings do not depend on the outside observer's estimated values for the other two bidders.

If a bidder wins the object, his earnings in a round will depend on both his profits in the auction and the outside observer's value estimate:

$($ Earnings $)=($ Value for the good $)-($ Winning bid $)+($ The outside observer's value estimate $) / 2$

Note that a bidder gets the same payoffs from the outside observer's estimate, win or lose. 


\section{Online Appendix B: Derivation of equilibrium bidding curves}

In this appendix, we derive the equilibrium bidding curves. Consider a setting with $n \geq 2$ bidders, indexed $i=1, \ldots, n$, bidding for a single, indivisible object. Bidders' values for the object are i.i.d. according to a smooth distribution function $F$ on $[0, \bar{v}], \bar{v}>0$. The auction outcome is partly revealed to an outside observer. We assume that a bidder's payoffs are increased by $\gamma \tilde{v}(\gamma>0)$, if the outside observer's estimate of the bidder's value equals $\tilde{v}$. For the analysis, we presume that bidders bid according to the same, strictly increasing, bidding curves. In equilibrium, the outside observer updates her beliefs about the bidders' values accordingly.

The structure of this appendix is as follows: in sections B.1 and B.2, we derive equilibrium bidding curves for settings in which the outside observer is informed about who wins the auctions and how much the winner pays in a first-price sealed-bid auction and second-price sealed-bid auction, respectively. In section B.3, we consider the case where the outside observer is only informed about the winner of the auction.

\section{B.1 First-price sealed-bid auction winner payment}

Assume that bidders bid according to a strictly increasing bidding curve $B(v)$. Now, consider a bidder with a value $v$ bidding as if his value were $w \in[0, \bar{v}]$. If the other bidders stick to the equilibrium bidding curve, this bidder's expected payoffs equal

$$
u(v, w)=F^{(1)}(w)(v-B(w)+\gamma w)+\gamma \int_{w}^{\bar{v}} \tilde{V}(x) d F^{(1)}(x)
$$

where $F^{(1)}$ denotes the distribution of the highest-order statistic of $n-1$ i.i.d. draws from $F$. The first term on the RHS refers to the case in which the bidder wins and then the outside observer induces that the bidder's value equals $w$. The second term is the bidder's payoff when losing the auction, where $\tilde{V}(x)$ denotes the outside observer's optimal value estimate for losing bidders. The equilibrium FOC is given by

$$
\begin{gathered}
\left.\frac{\partial u(v, w)}{\partial w}\right|_{w=v}=f^{(1)}(v)(v-B(v)+\gamma v)-F^{(1)}(v)\left(B^{\prime}(v)-\gamma\right)-\gamma \tilde{V}(v) f^{(1)}(v)=0 \\
\Leftrightarrow f^{(1)}(v)(B(v)-\gamma v)+F^{(1)}(v)\left(B^{\prime}(v)-\gamma\right)=(v-\gamma \tilde{V}(v)) f^{(1)}(v),
\end{gathered}
$$


where $f^{(1)}$ is the density function corresponding to $F^{(1)}$. Taking into account the boundary condition $B(v)=0$, we find the following solution for the resulting differential equation:

$$
B(v)=\frac{\int_{0}^{v}(x-\gamma \tilde{V}(x)) d F^{(1)}(x)}{F^{(1)}(v)}+\gamma v
$$

For the parameters used in the experiment $(\gamma=1 / 2, n=3, F=U[0,1])$, we have $\tilde{V}(x)=x / 2$ and $F^{(1)}(v)=v^{2}$ from which it follows that $B(v)=v$.

\section{B.2 Second-price sealed-bid auction winner payment}

The analysis for the second-price sealed-bid auction is analogous to the first. Let $F^{(2)}(w \mid x)$ denote the distribution of the second highest value among the $n-1$ other bidders if a bidder pretends to have value $w$, conditional on the highest value among the other bidders being $x$. Moreover, we will let $V(x)$ represent the outside observer's estimate of the winner's value, conditional on the second-highest value being $x$. We then have:

$$
u(v, w)=\int_{0}^{w}(v-B(x)+\gamma V(x)) d F^{(1)}(x)+\gamma \int_{w}^{\bar{v}} \tilde{v}(x \mid w) d F^{(1)}(x) .
$$

where $\tilde{v}(x \mid w)=w F^{(2)}(w \mid x)+\int_{w}^{x} \frac{y}{2} d F^{(2)}(y \mid x)$ represents the expected value of the outside observer's value estimate of a bidder who bids as if having value $w$, conditional on the highest value among the $n-1$ other bidders being $x$. Notice that $\lim _{w \uparrow x} \tilde{v}(x \mid w)=$ $x$.

The equilibrium FOC:

$$
\begin{gathered}
(v-B(v)+\gamma V(v)) f^{(1)}(v)-\gamma \lim _{v \uparrow w} \tilde{v}(v \mid w) f^{(1)}(v)+\gamma \int_{v}^{\bar{v}} \frac{\partial \tilde{v}(x \mid v)}{\partial w} d F^{(1)}(x)=0 \Leftrightarrow \\
B(v)=(1-\gamma) v+\gamma V(v)+\gamma \int_{v}^{\bar{v}} \frac{\partial \tilde{v}(x \mid v)}{\partial w} d F^{(1)}(x) / f^{(1)}(v) .
\end{gathered}
$$

For the parameters used in the experiment, $B(v)=v / 2+5 / 8$. 


\section{B.3 Winner-only, both auction types}

The predictions for the winner-only treatments are straightforward: bidders' equilibrium bids are the standard equilibrium bids in a setting without outside observer inflated by $\gamma$ times the difference between the outside observer's value estimates for the winner and the losing bidders. When estimating a bidder's value, the outside observer minimizes w.r.t. $w$ :

$$
\int_{0}^{\bar{v}}|w-v| d G(v)=\int_{0}^{w}(w-v) d G(v)+\int_{w}^{\bar{v}}(v-w) d G(v)
$$

where $G$ is the outside observer's belief, i.e., the distribution function of the bidder's value. The FOC:

$$
\int_{0}^{w} d G(v)-\int_{w}^{\bar{v}} d G(v)=0 \Leftrightarrow 2 G(w)-1=0 .
$$

For the three-bidder case, with values uniformly distributed on $[0,100], G(v)=v^{3} / 10^{6}$ for the winning bidder, under the assumption that bidders submit bids according to the same strictly increasing bidding curve. This implies that the outside observer's best guess equals $w=100 / \sqrt[3]{2} \approx 79$. W.r.t. the guesses for the losing bidders, $G(v)=\frac{3 v}{200}-$ $\left(v^{3} / 2\right) / 10^{6}$. The outside observer's optimal guess is approximately equal to 35 . The difference between the estimates equals about 44, which translates to the inflation of bids by 22 . 


\section{Online Appendix C: Additional figures}

Table C.1: Bids submitted

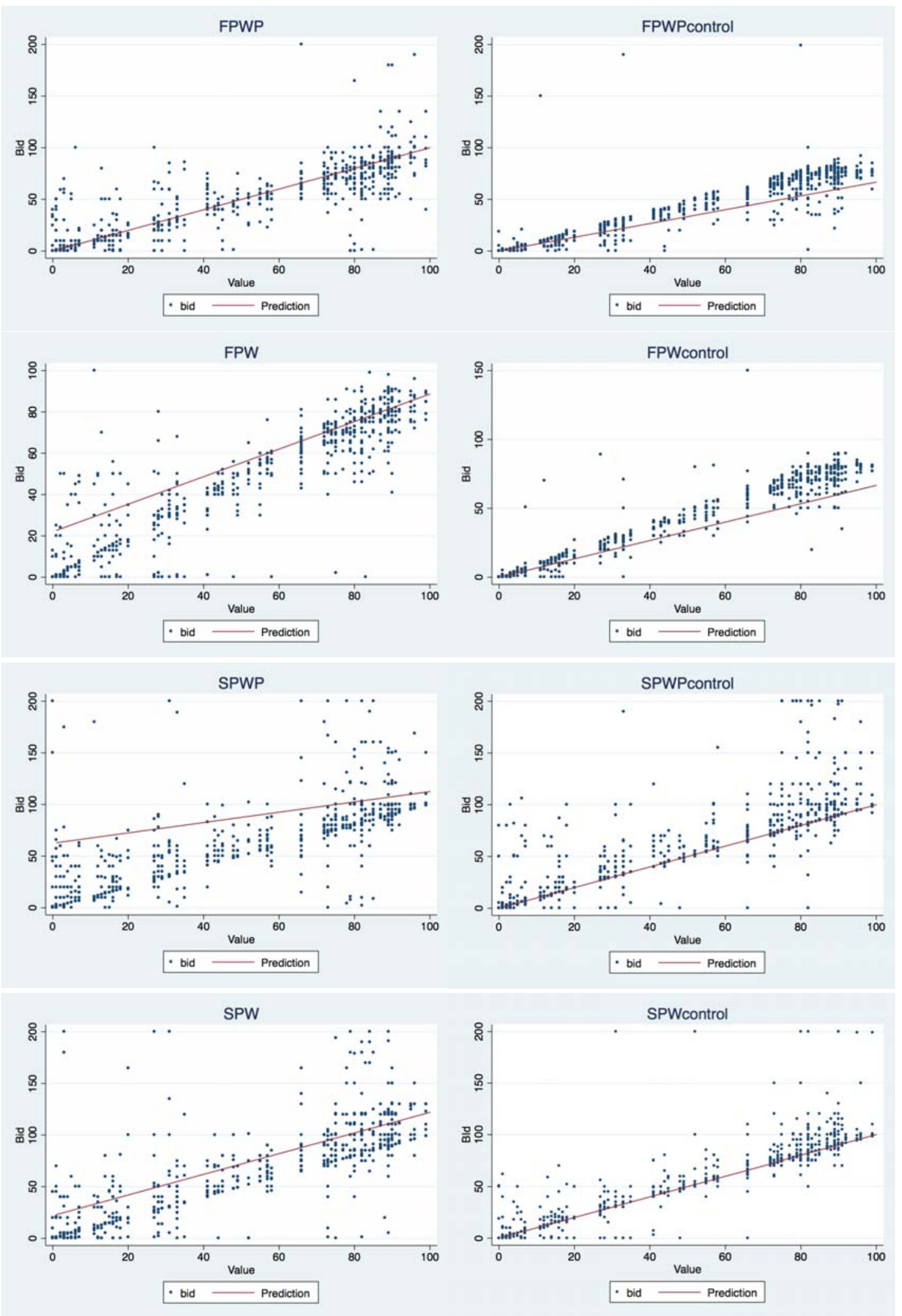

Notes: The solid lines refer to the equilibrium bidding curves 
Table C.2: Average outside observer's estimates, and average bidder's values, conditional on winner's payment for the FP auction

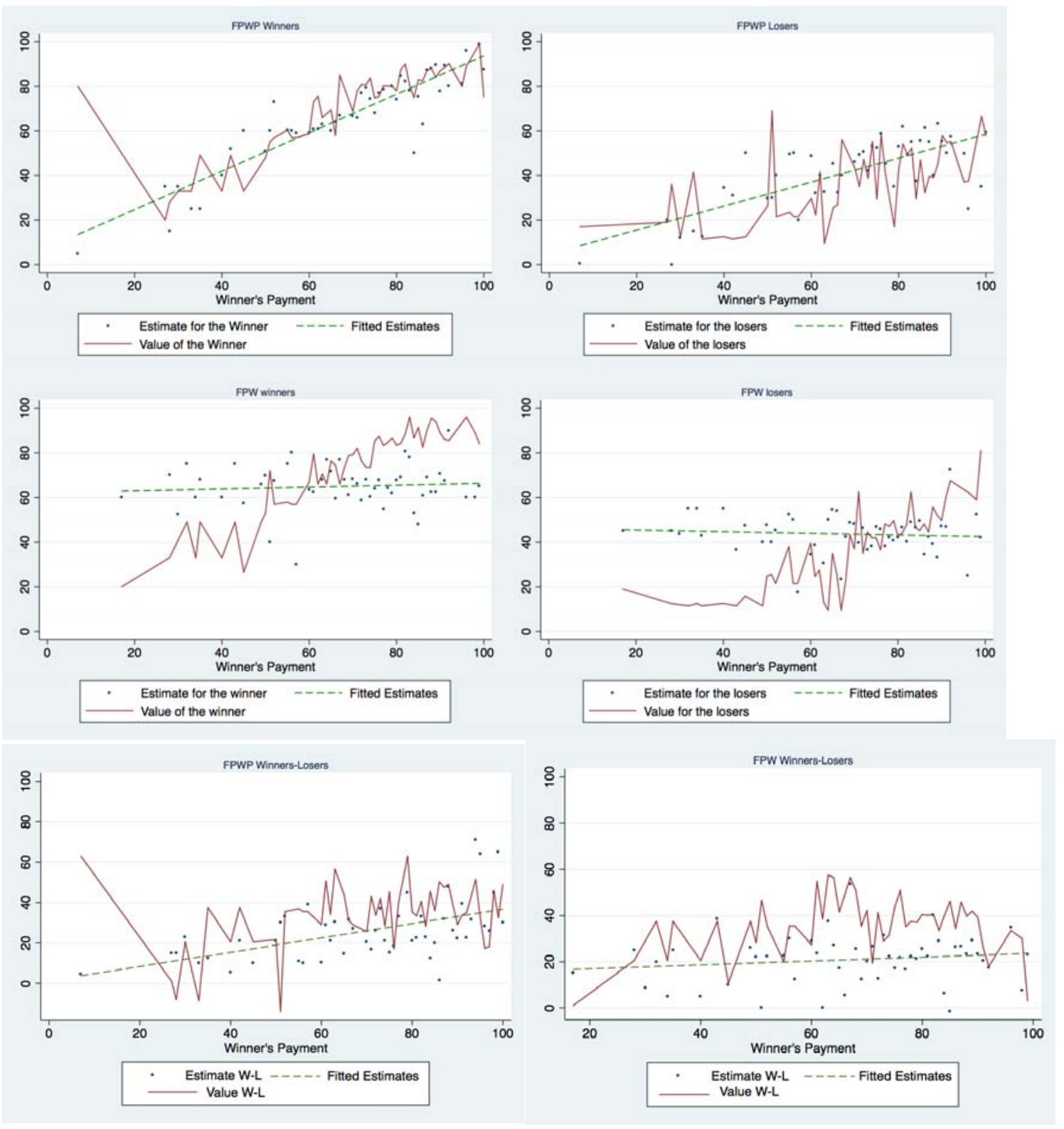

Notes: The dots represent the outside observers' value estimates; solid lines refer to the actual values of the bidders; the dashed lines are the outcomes of linear regressions of the outsider observers' value estimates on the winner payment; the two panels at the bottom plot the difference in the outside observers' value estimates between winning and losing bidders. 
Table C.3: Average outside observer's estimates and average bidder's values for each winner's payment for the SP auction
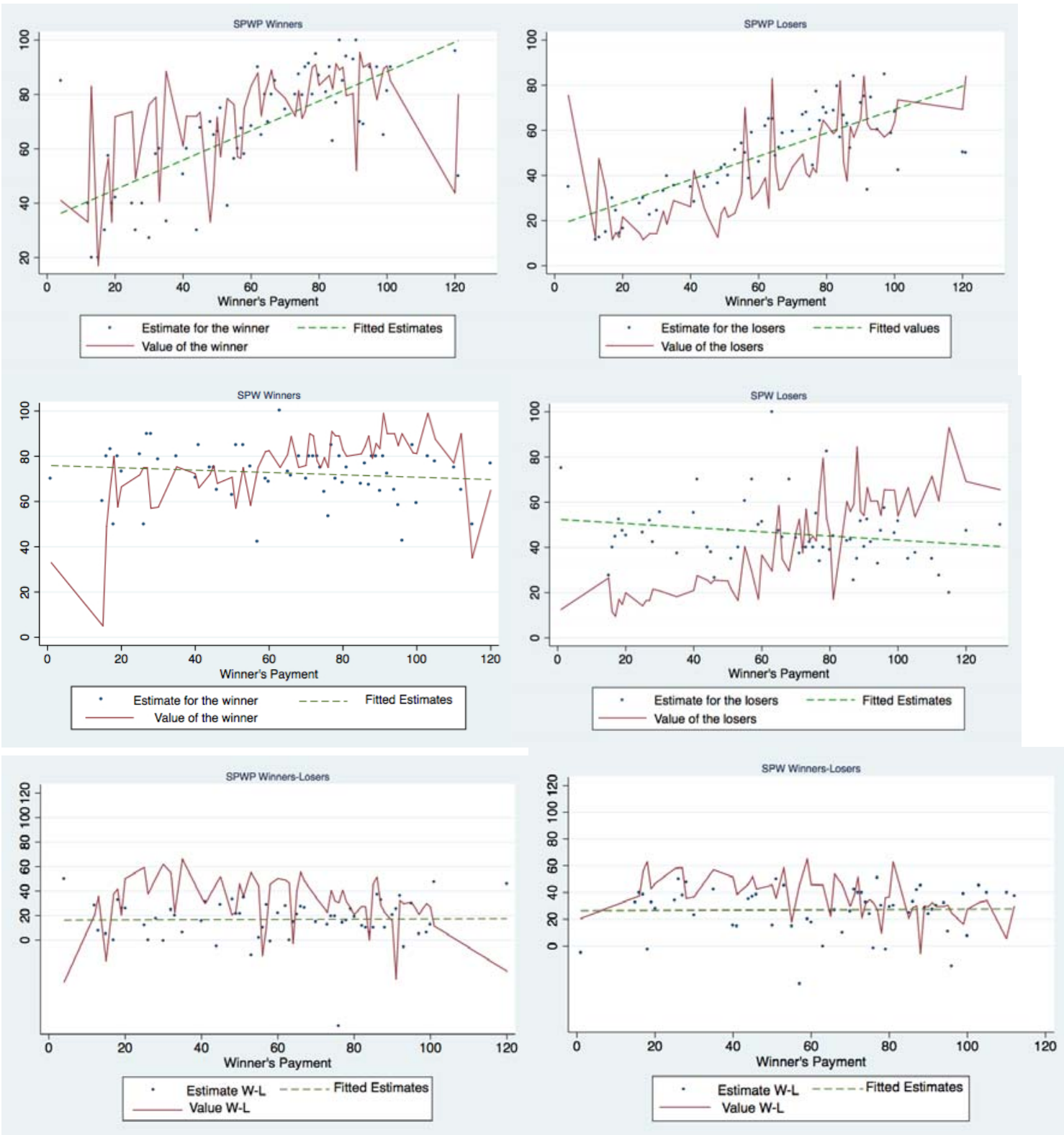

Notes: The dots represent the outside observers' value estimates; solid lines refer to the actual values of the bidders; the dashed lines are the outcomes of linear regressions of the outsider observers' value estimates on the winner payment; the two panels at the bottom plot the difference in the outside observers' value estimates between winning and losing bidders. 